\title{
ANÁLISE E MENSURAÇÃO DA SATISFAÇÃO DE USUÁRIOS DE SISTEMAS DE SUSTENTAÇÃO DE ROÇADEIRAS LATERAIS MOTORIZADAS
}

\section{ANALYSIS AND MEASUREMENT OF THE SATISFACTION OF USERS OF GASOLINE BRUSH CUTTERS}

\author{
Daniel Augusto Ferrari ${ }^{1}$, M.e \\ Luís Carlos Paschoarelli ${ }^{2}$ LD \\ Gabriel Henrique Cruz Bonfin ${ }^{3}$, M.e \\ João Eduardo Guarnetti dos Santos ${ }^{4}, \mathrm{LD}$ \\ (1) Unesp/Ceeteps \\ e-mail: daniel.ferrari@etec.sp.gov.br \\ (2) Unesp \\ e-mail:paschoarelli@faac.unesp.br \\ (3) Unesp \\ e-mail:gh_cb@hotmail.com \\ (4) Unesp \\ e-mail: guarneti@feb.unesp.br
}

Palavras-chave: Design Ergonômico, Roçadeiras Laterais Motorizadas, Análise de Satisfação

As Roçadeiras Laterais Motorizadas, equipamentos manuais destinados ao corte de vegetações, apresentam interfaces de sustentação que podem trazer sérios riscos ergonômicos. Este estudo propôs a aplicação de um questionário de avaliação subjetiva de usabilidade à utilizadores desses sistemas visando investigar possíveis falhas ou acertos no design desses equipamentos.

Key-words: Ergonomic Design, Gasoline Brush Cutters, Satisfaction analysis

Gasoline brush cutters are manual equipment for vegetation cutting, which have support interfaces that can cause serious ergonomic risks. This study proposed the application of a questionnaire of subjective evaluation of usability 
$16^{\circ}$ USIHC - Congresso Internacional de Ergonomia e Usabilidade de Interfaces Humano Computador

CINAHPA | 2017 - Congresso Internacional de Ambientes Hipermídia para Aprendizagem.

to the users of these systems in order to investigate possible failures or success in the design of these equipments.

\section{Introdução}

Diariamente, um sem número de indústrias de bens de produção, consumo e serviços, desenvolvem produtos focando maior ênfase na eficiência econômica e financeira, por outro lado empregam menor importância aos aspectos humanos como: sustentabilidade social, ambiental e da relação de segurança e inteligibilidade de interfaces homem $\mathrm{x}$ produto, referindo-se aqui aos fatores humanos.

Estudos inerentes à Ergonomia e Usabilidade, que se utilizam de diversas áreas da ciência focando o bem estar humano, caminham a passos largos no sentido de corrigir e, até mesmo, antecipar possíveis falhas entre o complexo sistema homem $\mathrm{x}$ máquina.

Especificamente no Brasil o mercado de ferramentas manuais cresce a cada ano e hoje nunca foi tão fácil adquirir um produto portátil. É tão amplo que abrange praticamente todos os ramos da economia, incluindo desde os setores da indústria e construção civil, passando pelo agrícola e de serviços, culminando nas residências através das ferramentas "hobby".

Em iguais proporções crescem os números de reclamações aos Serviços de Atendimento aos Consumidores (SAC's), muitas vezes decorrentes do uso indevido do equipamento, ora pela não leitura ou incompreensão dos manuais de instrução, ora por falta de treinamento, ora por falhas no projeto da interface do desenho do produto.

No que diz respeito ao setor agrícola nota-se, especialmente nesta última década, um aumento do interesse em desenvolver e implementar intervenções ergonômicas na agricultura em todo o mundo [FATHALLAH, 2010].

Entretanto tem-se notado que os distúrbios musculoesqueléticos estão entre os problemas mais comuns dentre todas as lesões e doenças não fatais identificadas em trabalhadores do campo, especialmente naqueles que se envolvem em práticas de trabalho intensivo [FATHALLAH, 2010; MCCURDY et al., 2003; MEYERS et al., 1997; VILLAREJO, 1998; VILLAREJO \& BARON, 1999].

As roçadeiras laterais motorizadas, utilizadas na limpeza da vegetação de áreas urbanas, florestais e rurais, enquadram-se na classe das ferramentas manuais e, segundo estudos recentes, nota-se uma relação de causalidade entre uso inadequado do equipamento e possíveis transtornos musculoesqueléticos.

Dentro desse contexto o referido estudo propõe-se avaliar o nível de satisfação de utilizadores de 4 diferentes interfaces de sustentação de roçadeiras laterais motorizadas através da aplicação de um questionário de avaliação subjetiva.

\section{Revisão de literatura}

\subsection{Características e postura de trabalho com Roçadeiras Laterais Motorizadas}

Uma Roçadeira Lateral Motorizada caracteriza-se num equipamento manual provido de um motor a combustão que transmite energia mecânica a um sistema de corte (lâminas de aço ou fios de nylon) por meio de uma haste rígida. Nesta haste estão fixados o suporte de sustentação, que prende o cinto de sustentação (ârnes) ao corpo do operador, e o suporte das empunhaduras (figura 1).
Realização:
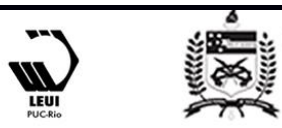


\section{$16^{\circ}$ \\ ERGODESIGN USIHC CINAHPA}

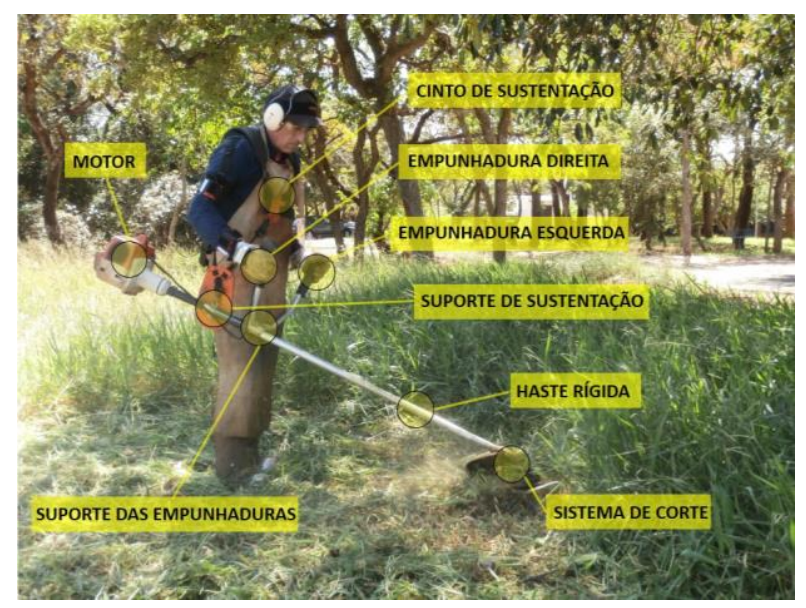

Figura 1 - Operador, Roçadeira Lateral Motorizada e seus componentes. Fonte: Elaborado pelo autor.

Sua ignição ocorre por meio do tracionamento de um cordão e uma mola espiral, ambos localizados na região traseira do equipamento. Seu controle se da através de um cabo flexível que liga o motor a um gatilho acelerador, localizado na empunhadura direita da máquina.

Estes equipamentos, além de oferecerem diversos riscos, exigem resistência e habilidade dos operadores, pois além de possuírem peso considerável, variando entre 6 a $13 \mathrm{Kg}$, demandam destreza na tarefa de "vesti-los", balanceá-los e opera-los. Segundo Gonzaga [2004], ferramentas apropriadas são constituídas de forma, peso e dimensões adequadas e, além de serem desenvolvidas com a finalidade de obter maior rendimento no trabalho, devem também proporcionar maior segurança aos trabalhadores.

Dentre os tópicos relevantes a serem considerados está a utilização incorreta do arnês (cinto de sustentação que liga a máquina ao usuário), pois seu uso incorreto pode permitir que o usuário trabalhe em uma postura inadequada.

No que se refere ao estudo da postura de trabalho na atividade com roçadeiras laterais motorizadas constata-se a carência de bibliografia específica, contudo foram encontrados alguns manuscritos que puderam nortear os rumos deste trabalho.

Em um estudo realizado por Fiedler et al., [2011], avaliando posturas adotadas em áreas declivosas $16^{\circ}$ Ergodesign - Congresso Internacional de Ergonomia e Usabilidade de Interfaces Humano Tecnológica: Produto, Informações Ambientes Construídos e Transporte

$16^{\circ}$ USIHC - Congresso Internacional de Ergonomia e Usabilidade de Interfaces Humano Computador

CINAHPA | 2017 - Congresso Internacional de Ambientes Hipermídia para Aprendizagem. concluíram que, dentre várias atividades exercidas por agricultores, a tarefa com roçadeiras necessitava de correções, pois esta atividade, segundo autores, poderia gerar problemas na coluna vertebral dentre outras doenças laborais que poderiam afetar o bem-estar físico do trabalhador.

Vergara et al., [2012], que realizou um estudo da atividade de jardinagem e paisagismo, classificaram a tarefa de roçagem como pouco dinâmica, ou seja, na maior parte do tempo o trabalhador executava movimentos repetitivos e com força constante. Concluíram que, para a melhoria da postura de trabalho, é fundamental que se faça o ajuste do equipamento, de modo a se adaptar melhor a postura do trabalhador, sugerindo também melhorias no cinto de sustentação da máquina.

Em um estudo realizado por Poletto Filho [2013], que analisou riscos físicos e ergonômicos em roçadeiras laterais motorizadas por meio da aplicação de questionário nórdico e EWA (Ergonomic Workplace Analysis), verificou que $100 \%$ dos usuários consideraram a atividade física ruim.

Dentro desse contexto, considerando os problemas apresentados em utilizadores do equipamento em estudo, é provável que relatos de dores e desconfortos tenham uma relação com a postura de trabalho inadequada. Tais dores podem ser potencializadas quando se faz o uso incorreto dos cintos de sustentação, bem como o ajuste indevido dos sistemas de regulagem das empunhaduras e balanceamento incorreto do produto, como pode ser visualizado na figura 2 .

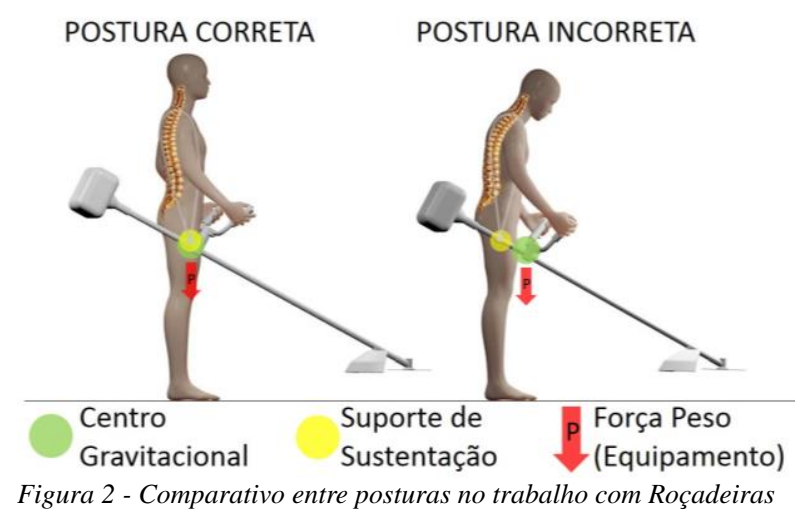

Realização:

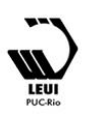

UNIVERSIDADE FEDERAL DE SANTA CATARINA 


\section{$16^{\circ}$ \\ ERGODESIGN USIHC CINAHPA}

$16^{\circ}$ Ergodesign - Congresso Internacional de Ergonomia e Usabilidade de Interfaces Humano Tecnológica: Produto, Informações Ambientes Construídos e Transporte

$16^{\circ}$ USIHC - Congresso Internacional de Ergonomia e Usabilidade de Interfaces Humano Computador

CINAHPA | 2017 - Congresso Internacional de Ambientes Hipermídia para Aprendizagem. laterais Motorizadas. Fonte: Elaborado pelo autor.

\subsection{Recomendações sobre o estudo das interfaces de sustentação de roçadeiras laterais motorizadas: vestimenta do cinto, montagem e regulagem para balanceamento.}

No que se refere à busca de instruções sobre procedimentos padronizados que se demonstrem adequados à utilização menos prejudicial à postura de trabalho com esses equipamentos foram encontradas informações muito dispersas em manuais de instruções e, na maioria das vezes, direcionadas a cada modelo em específico. A norma ISO 11806-1 - 20111 [ISO, 2011] recomenda que o balanceamento da máquina consiste em permitir que o operador, através de sistemas de regulagens, possa ajustar o equipamento de modo que o mesmo fique em equilíbrio, proporcionando a correta altura do mecanismo de corte em relação ao solo e consequentemente uma postura confortável (Figura 3). Este procedimento deve ser feito com o tanque de combustível na metade de sua capacidade total mas com o equipamento totalmente desligado.

As informações sobre instruções de vestimenta e balanceamento que se apresentaram mais adequadas e em consonância com a ISO 11806-12011 são demonstradas por Government South Australia [2000], a seguir:

- O primeiro passo consiste na ajustagem do "gancho" do cinto de sustentação, que deve ficar a aproximadamente 15 centímetros abaixo do osso ilíaco (Figura 3-1).

- Em um segundo momento o operador deverá soltar as empunhaduras de modo que o equipamento adquira equilíbrio suficiente para que a lâmina, dependendo do tipo de vegetação a ser roçada, fique entre 10 a 30 centímetros do solo (figura 3-2).

${ }^{1}$ Norma que apresenta os requisitos de segurança e medidas para a sua verificação, concepção e construção de portáteis alimentados, roçadeiras portáteis e aparadores de relva (doravante denominado máquinas) com um motor de combustão integral e sua unidade de potência e transmissão de energia mecânica entre a fonte de energia e equipamento de corte.
- A terceira etapa compreende na regulagem das empunhaduras, de modo que haja distribuição do peso entre os braços (figura 3-3).

- A quarta e última etapa consiste em novamente soltar as empunhaduras de maneira que a lâmina paire e centralize igualmente sobre o eixo longitudinal do operador (figura 3-4).

Este simples procedimento, dependendo da interface oferecida, pode permitir que a carga total do equipamento fique igualmente distribuída sobre os ombros, deixando os braços livres para realizar apenas a movimentação lateral.

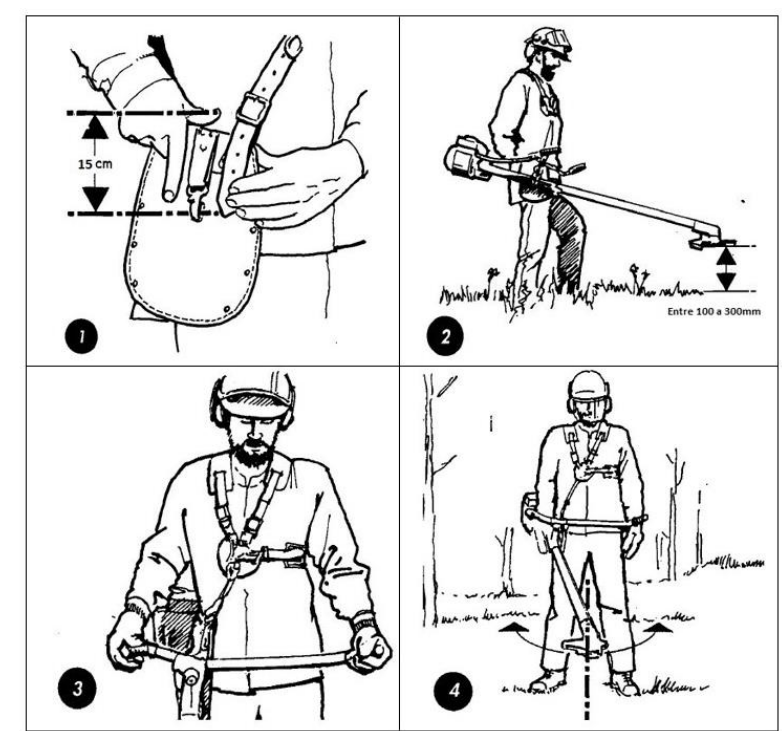

Figura 3 - Procedimentos básicos para o balanceamento de roçadeiras laterais motorizadas. Fonte: Government South Australia [2000].

\subsection{Usabilidade}

Usabilidade, de acordo com a própria terminologia da palavra, tem como foco investigar como as pessoas usam o produto, no que refere a interação entre usuário, a tarefa e o produto. É notório que no passado muitos produtos eram projetados com pouca ênfase no usuário, ocasionando frustrações e desperdício de tempo por não oferecerem o uso amigável. [JORDAN, 1998; NORMAN, 2006; PREECE et al., 2002; GÖBEL, 2011]. Com a expansão e a saturação do mercado, bem como a queda das diferenças tecnológicas, aspectos como a estética e a usabilidade passaram a ser
Realização:

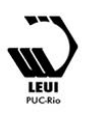




\section{$16^{\circ}$ \\ ERGODESIGN USIHC CINAHPA}

primordiais. Diante do exposto a usabilidade fixa como objetivo alcançar a qualidade de uso, ou seja, buscar a satisfação das necessidades do usuário e é de primordial importância a inclusão desse objetivo já no processo de desenvolvimento de um determinado produto ou sistema. Nielsen [1993], considera usabilidade como um aspecto, entre outros, que influencia na aceitação de um produto, cujo objetivo consiste em elaborar interfaces transparentes, capazes de oferecer uma interação fácil, agradável, com eficácia e eficiência, permitindo ao usuário pleno controle do ambiente sem se tornar um obstáculo durante a interação.

A Norma ISO 9241-11 [ISO, 1998] descreve o conceito de usabilidade como sendo: "o alcance pelo qual um produto pode ser usado por certos usuários visando atingir objetivos específicos com eficácia, eficiência e satisfação em um determinado contexto de uso" onde:

Eficácia - consiste na precisão e completeza com que os usuários atingem objetivos específicos.

Eficiência - refere-se a quantidade de esforço de aprendizagem ou tempo requerido para se atingir um certo objetivo.

Satisfação - concerne ao conforto e a presença de atitudes positivas que o usuário sente quando usa um produto e o quão é aceitável em relação ao desejo de atingir os seus objetivos.

\begin{tabular}{|c|c|c|c|}
\hline $\begin{array}{l}\text { Objetivos de } \\
\text { Usabilidade }\end{array}$ & $\begin{array}{l}\text { Medidas de } \\
\text { Eficácia }\end{array}$ & $\begin{array}{l}\text { Medidas de } \\
\text { Eficiência }\end{array}$ & $\begin{array}{c}\text { Medidas de } \\
\text { Satisfação }\end{array}$ \\
\hline \multirow{3}{*}{$\begin{array}{c}\text { Usabilidade } \\
\text { Global }\end{array}$} & $\begin{array}{l}\text { Porcentagem } \\
\text { de objetivos } \\
\text { alcançados; }\end{array}$ & $\begin{array}{l}\text { Tempo para } \\
\text { completar } \\
\text { uma tarefa; }\end{array}$ & $\begin{array}{l}\text { Escala de } \\
\text { satisfação }\end{array}$ \\
\hline & $\begin{array}{l}\text { Porcentagem } \\
\text { de usuários } \\
\text { completando } \\
\text { a tarefa com } \\
\text { sucesso; }\end{array}$ & $\begin{array}{l}\text { Tarefas } \\
\text { completadas } \\
\text { por unidade } \\
\text { de tempo; }\end{array}$ & $\begin{array}{l}\text { Frequência de } \\
\text { uso arbitrário; }\end{array}$ \\
\hline & $\begin{array}{c}\text { Média de } \\
\text { acurácia de } \\
\text { tarefas } \\
\text { completadas; }\end{array}$ & $\begin{array}{l}\text { Custo } \\
\text { monetário de } \\
\text { realização da } \\
\text { tarefa; }\end{array}$ & $\begin{array}{l}\text { Frequência de } \\
\text { reclamações; }\end{array}$ \\
\hline
\end{tabular}

Tabela 1- Exemplo de medidas de usabilidade ISO 9241-11. Fonte: [ISO, 1998]

Enfim, o Contexto do uso refere-se a parâmetros externos ás propriedades materiais do produto em $16^{\circ}$ Ergodesign - Congresso Internacional de Ergonomia e Usabilidade de Interfaces Humano Tecnológica: Produto, Informações Ambientes Construídos e Transporte

$16^{\circ}$ USIHC - Congresso Internacional de Ergonomia e Usabilidade de Interfaces Humano Computador

CINAHPA | 2017 - Congresso Internacional de Ambientes Hipermídia para Aprendizagem.

si e sinaliza a importância das características do usuário, do objetivo que pretende atingir e em que ambiente o produto está sendo utilizado.

Estudos anteriores, propostos pelos autores, tiveram como foco avaliar medidas de "Eficácia" e "Eficiência" de sistemas de sustentação de roçadeiras laterais motorizadas. Neste experimento a pesquisa teve como objetivo principal avaliar a satisfação dos usuários através de um questionário de avaliação subjetiva criado especificamente para tal produto.

\subsection{SUS}

O protocolo SUS (System Usability Scale) foi idealizado por John Brooke em 1986 enquanto trabalhava na Digital Equipment Corporation. Trata-se de um questionário de avaliação subjetiva de usabilidade, utilizado ao final de uma experiência de interação com um determinado produto. Caracteriza-se uma ferramenta de grande importância na avaliação global de usabilidade de uma interface, além de ser um mecanismo de apreciação muito eficaz e barato.

Dentre suas várias características positivas está a possibilidade de ser aplicado, de maneira rápida, logo após a interação.

O SUS foi pensando para agilizar o processo de coleta de dados e recomenda-se ser estruturado em até 10 declarações. Segundo Lanutti et al [2014] após uma interação, da qual se deseja coletar as medidas subjetivas de usabilidade, é presumível que os usuários apresentem-se fatigados, especialmente se tiveram dificuldades no uso, pois nenhuma assistência pode ser oferecida em testes dessa natureza. Portanto, ao serem apresentados a um questionário com muitas perguntas, torna-se muito provável que tais usuários o completem com respostas "jogadas ao acaso", contabilizando dados inexpressivos para avaliar informações subjetivas de usabilidade [BROOKE,1996].

O SUS trabalha com afirmações de visão global metade de forte acordo (afirmativas) e metade de discordância (negativa) - através da escala de Likert com 5 ou 7 pontos, onde uma declaração é feita e em seguida o entrevistado indica um grau de concordância ou discordância da afirmação [BROOKE, 1996]. 


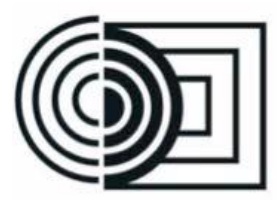

A inclusão de sentenças positivas e negativas é realizada buscando evitar distorções causadas pela resposta dos entrevistados que não querem se preocupar em ler todas as declarações, com isso, alternando itens positivos e negativos, o voluntário tem que ler cada declaração e fazer um esforço para pensar se concordam ou não [BROOKE,1996].

\section{Objetivo}

O presente estudo tem como objetivo avaliar a satisfação dos usuários no tocante a experiência com o uso de 4 diferentes interfaces de sustentação de roçadeiras laterais motorizadas utilizando um questionário específico baseado no método de avaliação subjetiva de usabilidade SUS.

\section{Metodologia}

\subsection{Materiais}

04 Modelos de Roçadeiras Laterais Motorizadas providas de motores 2 tempos, faixas de potência entre 1,2 e 1,7 hp, possuindo diferentes interfaces em seus sistemas de sustentação (Figuras 4, 5 e 6). Tais equipamentos serão aqui denominados: Modelo A, B, C e D.

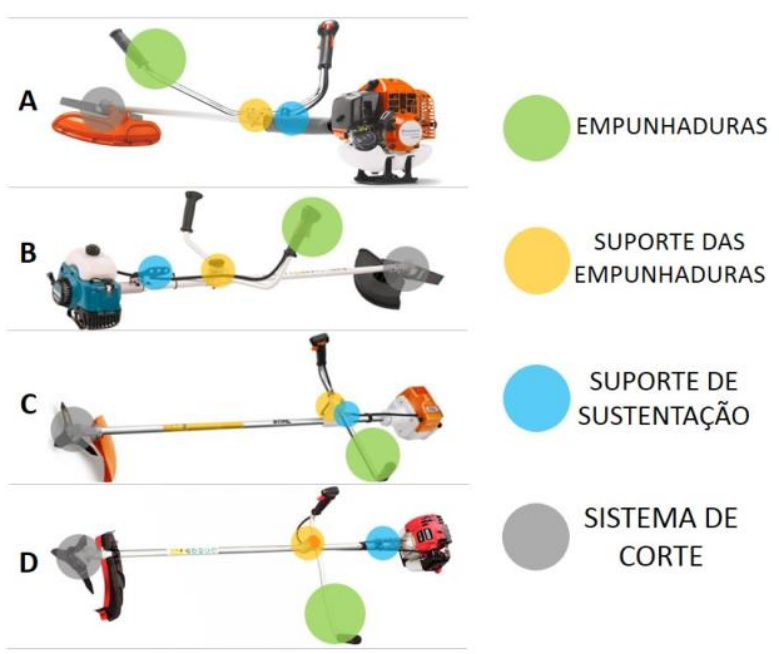

Figura 4- Equipamentos analisados - vocabulário técnico. $16^{\circ}$ Ergodesign - Congresso Internacional de Ergonomia e Usabilidade de Interfaces Humano Tecnológica: Produto, Informações Ambientes Construídos e Transporte

$16^{\circ}$ USIHC - Congresso Internacional de Ergonomia e Usabilidade de Interfaces Humano Computador

CINAHPA | 2017 - Congresso Internacional de Ambientes Hipermídia para Aprendizagem.

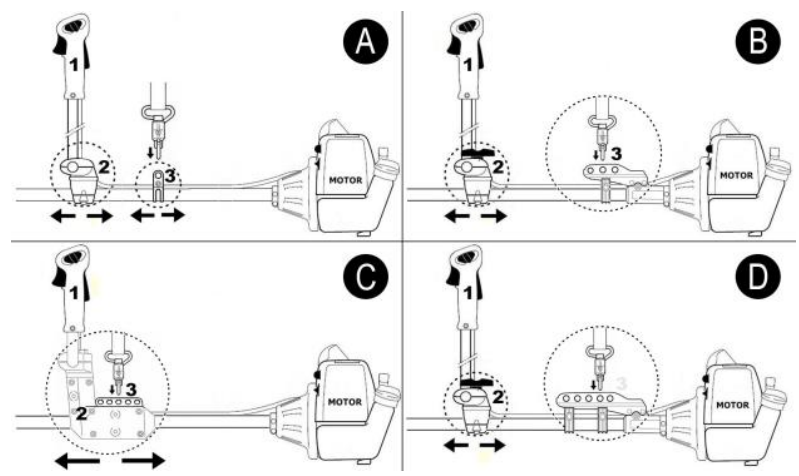

Figura 5 - Representação esquemática dos 4 sistemas de sustentação analisados.

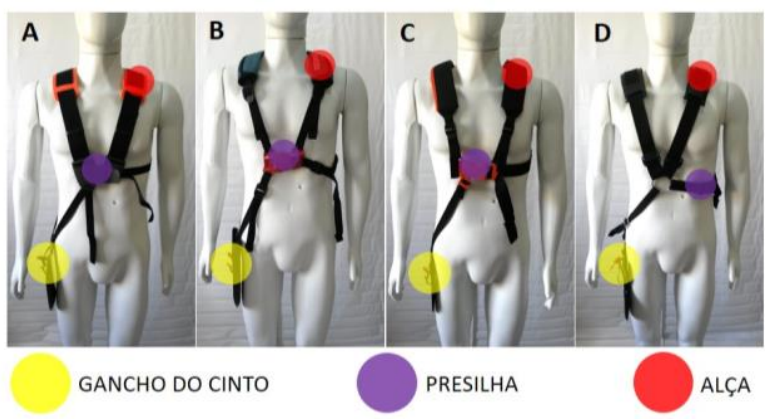

Figura 6 - Cintos de sustentação (arneses) analisados - vocabulário técnico.

\subsection{Sujeitos}

A pesquisa contou com a participação de 40 usuários em potencial, que apresentaram as seguintes características:

- Todos do sexo masculino;

- Faixa etária variando entre 18 e 44 anos (média = 24,5 e d.p. $=7,12$ );

- Peso, alternando entre 46 e 117 quilos (média = 72,9 e d.p. $=14,3$ );

- Estatura, variando entre 158 e 190 centímetros (média $=175,7$ e d.p. 6,6);

- Todos afirmaram possuir plenas condições físicas e mentais para realização do experimento;

- Todos alegaram serem alfabetizados;
Realização:

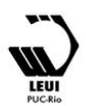




\section{$16^{\circ}$ \\ ERGODESIGN USIHC CINAHPA}

- Quatro sujeitos se declararam canhotos.

- Todos declararam nunca haverem manuseado ou mesmo presenciado a qualquer experiência de montagem de qualquer tipo de roçadeira lateral motorizada.

Todos leram e assinaram o Termo de

Consentimento Livre e Esclarecido

(CAAE: 44196815.8.0000.5663)

\subsection{Métodos}

O experimento se sucedeu no seguinte contexto: Os participantes eram convidados a montar as empunhaduras de uma das roçadeiras (Figura $4 \mathrm{e}$ 5), realizar a vestimenta do cinto de sustentação (Figura 6) bem como efetuar o ajuste para balanceamento, seguindo os procedimentos básicos de ajuste e balanceamento de roçadeiras laterais motorizadas proposto por Government South Australia [2000], apresentados na figura 3.

A obrigatoriedade da leitura dos procedimentos básicos de ajuste e balanceamento fez-se necessária devido a inexistência dessa orientação nos manuais de instruções de todos os equipamentos submetidos à análise.

Torna-se pertinente salientar que todos os equipamentos apresentavam-se exatamente com suas configurações iniciais de fábrica. Componentes integrantes do produto, como ferramentas e manual de instruções, também foram disponibilizados, este último não havendo a obrigatoriedade de leitura.

A escolha dos equipamentos ocorreu de maneira randômica, não havendo imposição de limites de tempo para realização da montagem, sendo pedido a cada participante que informasse o pesquisador quanto ao término do procedimento.

Após término do procedimento de balanceamento era solicitado a cada participante que permanecesse em posição de trabalho e que o mesmo simulasse os movimentos típicos desta atividade por 3 minutos. É importante ressaltar que o equipamento encontrava-se desligado. Outra importante observação a ser salientada refere-se ao peso dos $16^{\circ}$ Ergodesign - Congresso Internacional de Ergonomia e Usabilidade de Interfaces Humano Tecnológica: Produto, Informações Ambientes Construídos e Transporte

$16^{\circ}$ USIHC - Congresso Internacional de Ergonomia e Usabilidade de Interfaces Humano Computador

CINAHPA | 2017 - Congresso Internacional de Ambientes Hipermídia para Aprendizagem.

equipamentos, que foram "igualados" com a inserção de pequenas placas de metal nas duas extremidades (abaixo do mecanismo de corte e abaixo do motor), totalizando $9 \mathrm{~kg}$ cada.

Em seguida cada sujeito era convidado a responder a um questionário baseado no método SUS contendo 10 afirmações, sendo 5 positivas e 5 negativas, estas alocadas de maneira intercalada. Todas as afirmações se referiam a experiência de cada sujeito no uso da interface que lhe foi designada. Ao lado de cada afirmação era disposta uma escala de Likert (Figura 7) contendo 5 quadrículas, onde foram atribuídos os seguintes pesos e significados:

- Quadrícula extrema esquerda (concordo totalmente);

- Quadrícula esquerda (concordo em partes);

- Quadrícula do meio (neutro, indiferente);

- Quadrícula direita (discordo em partes);

- Quadrícula extrema direita (discordo totalmente).

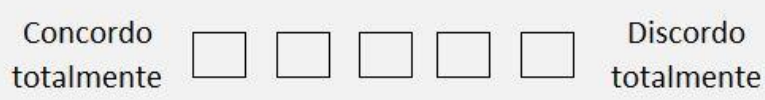

Figura 7 - modelo de respostas

\section{Resultados e Discussão}

Ainda que tenha sido observado que grande parte dos sujeitos apresentaram importantes dificuldades na montagem das empunhaduras durante $o$ experimento, de maneira geral, houve um considerável nível de concordância com a afirmativa apresentada no gráfico 1. Os sujeitos que participaram da montagem do equipamento modelo "C" relataram maior concordância em relação a facilidade de montagem desse sistema (9 votos), se comparado aos outros modelos analisados. Segundo observação da atividade, 


\section{$16^{\circ}$ \\ ERGODESIGN USIHC CINAHPA}

realizada em estudos anteriores, seu suporte de sustentação, integrado ao suporte das empunhaduras, proporcionou um procedimento menos complexo aos utilizadores.

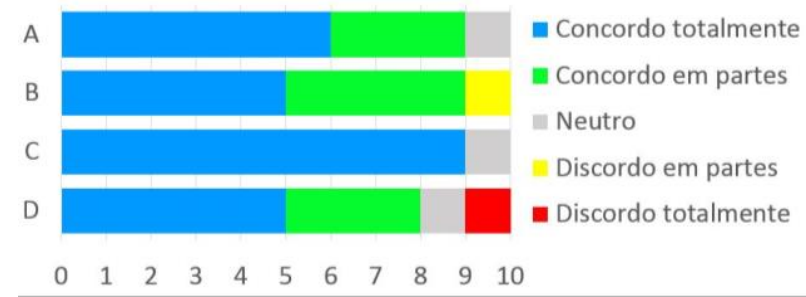

Gráfico 1 - A montagem das empunhaduras é fácil.

Por outro lado, os sujeitos participantes do experimento de montagem com o equipamento modelo "D" atribuíram menor concordância em relação aos demais modelos analisados (4 votos para concordância total e 1 voto para total discordância). Dentre as maiores dificuldades observadas na montagem das empunhaduras do modelo "D" estiveram: dúvidas sobre a ordem correta de encaixe dos acessórios que compõem o sistema de travamento das empunhaduras, bem como a montagem invertida das mesmas (empunhadura de aceleração disposta no lado esquerdo do equipamento).

Questionados sobre a possibilidade de montagem das empunhaduras sem o uso do manual de instruções as pontuações demonstraram que, de maneira geral, os participantes atribuíram certa indiferença sobre o conteúdo apresentado pelos manuais de instruções (gráfico 2). É importante ressaltar que estudos anteriores sobre eficácia e eficiência dos mesmos sistemas com os mesmos grupos de participantes, demonstraram que todos os 40 sujeitos realizaram leitura prévia dos manuais, mesmo não havendo a obrigatoriedade. Uma média geral de 2 minutos e 21 segundos foram despendidos para tal leitura. Dessa forma é provável que os conteúdos dispostos nos manuais possam não ter oferecido todas as instruções necessárias para a montagem dos sistemas. $16^{\circ}$ Ergodesign - Congresso Internacional de Ergonomia e Usabilidade de Interfaces Humano Tecnológica: Produto, Informações Ambientes Construídos e Transporte

$16^{\circ}$ USIHC - Congresso Internacional de Ergonomia e Usabilidade de Interfaces Humano Computador

CINAHPA | 2017 - Congresso Internacional de Ambientes Hipermídia para Aprendizagem.

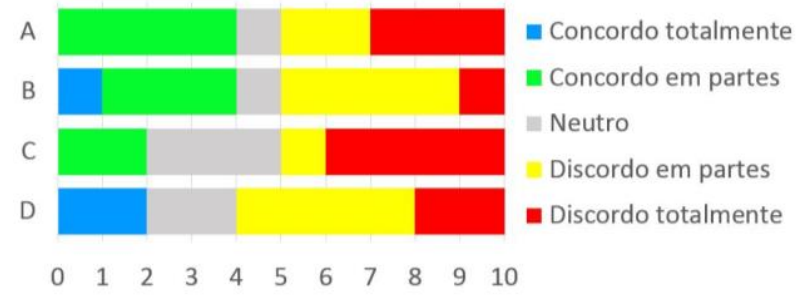

Gráfico 2 - Não é possível montar as empunhaduras sem o uso do manual de instruções.

Com referência a questão sobre a facilidade de regulagem do suporte de sustentação os sujeitos participantes da montagem com o equipamento modelo "C" atribuíram o maior número de concordância entre os 4 modelos analisados ( 8 pontos), como pode ser visto no gráfico 3 .

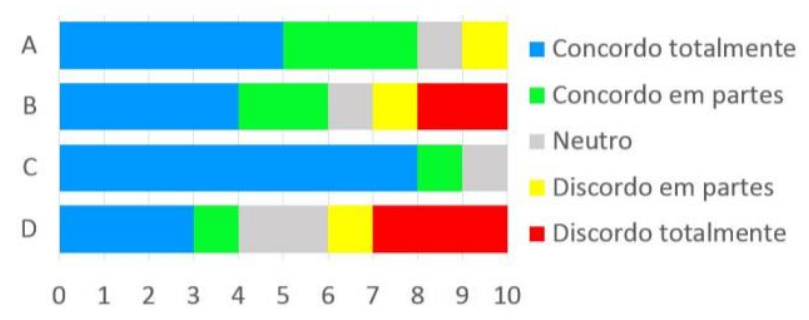

Gráfico 3- O suporte de sustentação, que prende a roçadeira ao gancho do cinto de sustentação (arnês), oferece fácil regulagem.

Novamente, pode-se atribuir tal pontuação ao fato de que, no equipamento modelo "C", o desenho do suporte das empunhaduras é integrado ao suporte de sustentação. Ademais, foi constatado que este elemento encontra-se posicionado bem próximo ao centro gravitacional da máquina, o que pode tornar mais fácil o procedimento de regulagem para balanceamento. Por outro lado, a média dos votos atribuídas pelos participantes do experimento com a máquina modelo " $\mathrm{D}$ " demonstrou-se absolutamente equilibrada. Tal ocorrência pode estar vinculada ao fato de que seu suporte de sustentação encontra-se fixo, o que impossibilita os usuários de realizarem regulagem de modo a buscar o balanceamento do sistema. A mesma conclusão pode ser atribuída aos participantes do experimento com o equipamento modelo "B", que também apresenta seu suporte de sustentação em posição fixa.

Em relação a questão referente a facilidade de regulagem das empunhaduras destaca-se o score de
Realização:

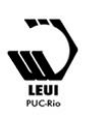




\section{$16^{\circ}$ \\ ERGODESIGN USIHC CINAHPA}

6 pontos de concordância com a negativa atribuída pelos usuários do equipamento modelo " $\mathrm{D}$ " (gráfico 4).

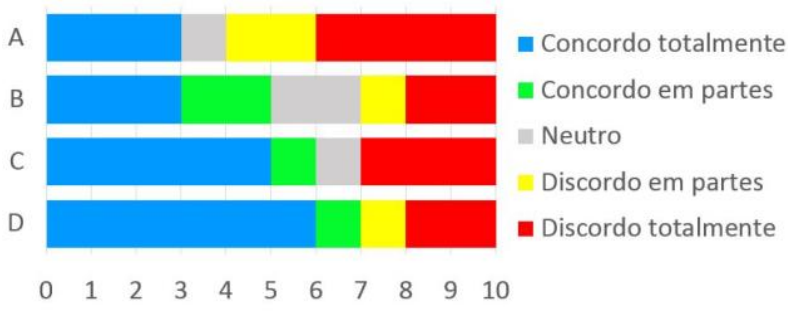

Gráfico 4 - Após montadas, as empunhaduras não permitem fácil regulagem para frente ou para trás, para direita ou para esquerda.

Em estudos anteriores foram observados notórias dificuldades de alguns usuários em realizar procedimentos de aperto ou desaperto do suporte das empunhaduras do modelo em questão, fato este que pode ter ocasionado relativa insatisfação de seus utilizadores. Por outro lado a pontuação de 4 votos de discordância, atribuída pelos utilizadores do sistema "A", pode estar vinculada ao fato de que o mecanismo em questão possui seus suportes (empunhaduras e sustentação) independentes e, apesar de pouco eficientes são relativamente funcionais. De maneira geral, nota-se que há prováveis deficiências em todos os sistemas apresentados, caso seja levado em consideração a não unanimidade nas respostas.

O gráfico 5 apresenta os níveis de concordância sobre a praticidade dos suportes de sustentação e das empunhaduras. Os maiores scores de total concordância foram atribuídos aos utilizadores dos sistemas "C" e " $A$ " (8 e 5 pontos) e podem estar relacionados ao fato de que foram os únicos equipamentos que proporcionaram eficácia no procedimento de balanceamento, conforme estudos anteriores. Por outro lado, $100 \%$ dos utilizadores que participaram do experimento de balanceamento como os modelos "B" e "D" não obtiveram êxito nesta tarefa, fato este que pode ter gerado insatisfação, consequentemente menores níveis de concordância. $16^{\circ}$ Ergodesign - Congresso Internacional de Ergonomia e Usabilidade de Interfaces Humano Tecnológica: Produto, Informações Ambientes Construídos e Transporte

$16^{\circ}$ USIHC - Congresso Internacional de Ergonomia e Usabilidade de Interfaces Humano Computador

CINAHPA | 2017 - Congresso Internacional de Ambientes Hipermídia para Aprendizagem.

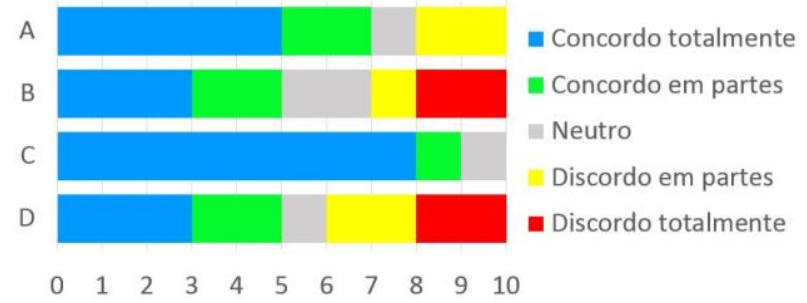

Gráfico 5 - O suporte das empunhaduras e o suporte de sustentação, elementos responsáveis pelo equilíbrio do equipamento, são práticos.

O gráfico 6 apresenta dados relacionados a uma afirmativa mais direta sobre o insucesso no procedimento de balanceamento de cada equipamento. Novamente os maiores scores que demonstraram concordância com a negativa (7 e 8 pontos) estão relacionados justamente aos usuários dos equipamentos que não proporcionaram eficácia no procedimento de balanceamento (equipamento modelo "B" e "D"). Apresentando maiores pontuações contrárias à negativa ficaram os utilizadores dos equipamentos modelo "A" e " $\mathrm{C}$ ".

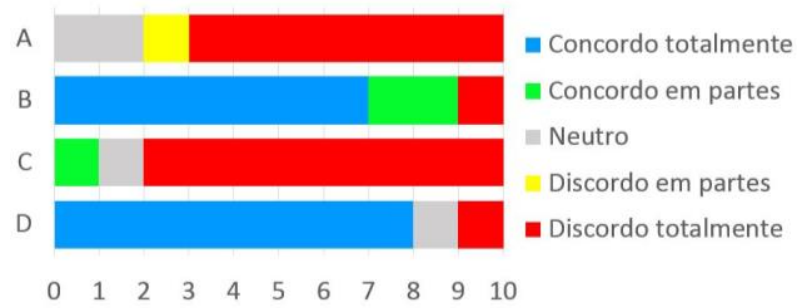

Gráfico 6 - Não consigo fazer o sistema de corte flutuar após soltar as duas mãos das empunhaduras.

É importante considerar que alguns utilizadores possam ter julgado não terem obtido o completo êxito no procedimento de balanceamento (modelo "A" e "C"), mesmo que para a equipe de pesquisadores tenha sido observada eficácia de todos os participantes desses modelos. Isso explica a não totalidade de concordância. $\mathrm{O}$ mesmo pode ser atribuído aos utilizadores dos equipamentos "B" e "D", que apesar de não terem atingido a eficácia no procedimento de balanceamento, podem ter julgado haver alguma outra forma de proceder com sucesso, o que explica a não totalidade de concordância com a negativa.

Os gráficos apresentados a seguir referem-se as questões inerentes a satisfação na experiência dos 


\section{$16^{\circ}$ \\ ERGODESIGN USIHC CINAHPA}

usuários com o uso dos cintos de sustentação (arneses).

Questionados sobre a oferta de estabilidade e segurança de cada arnês (gráfico 7) os participantes do experimento com o acessório modelo "D" foram os que atribuíram maior equilíbrio entre concordância e discordância com a afirmativa em questão. Conforme verificado em estudos anteriores, envolvendo a observação direta da atividade, observou-se que grande parte dos sujeitos não conseguiram realizar a correta regulagem de modo com que as alças acomodassem confortavelmente em seus ombros, pois suas "fivelas" se demonstraram confusas. O cinto modelo "A" apresentou maior score de concordância dentre os demais.

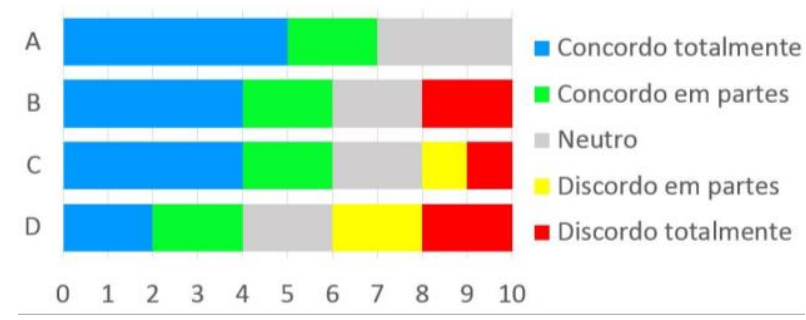

Gráfico 7 - O cinto de sustentação (arnês) me oferece estabilidade e segurança.

Outra questão apresentada referia-se a uma negativa sobre o conforto dos respectivos cintos (gráfico 8). De maneira geral pode-se afirmar que não houve unanimidade nas respostas de todos 4 modelos analisados, fato este que atesta a hipótese de que existe problemas de ordem ergonômica nestes acessórios. Os participantes do experimento com o acessório modelo "B" relataram maior pontuação de discordância com a negativa (5 pontos).

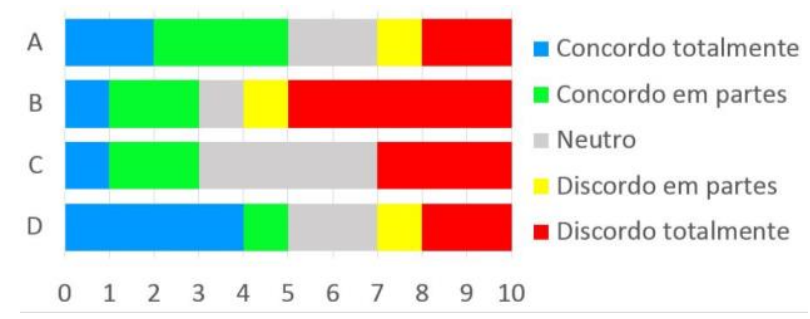

Gráfico 8 - O cinto de sustentação (arnês) não é confortável. $16^{\circ}$ Ergodesign - Congresso Internacional de Ergonomia e Usabilidade de Interfaces Humano Tecnológica: Produto, Informações Ambientes Construídos e Transporte

$16^{\circ}$ USIHC - Congresso Internacional de Ergonomia e Usabilidade de Interfaces Humano Computador

CINAHPA | 2017 - Congresso Internacional de Ambientes Hipermídia para Aprendizagem.

Novamente os participantes do experimento com o acessório modelo "D" demonstraram maior número de pontos de concordância com a negativa (4 pontos). Mais uma vez, a frustação da maioria dos usuários desse modelo pode ser atribuída à prováveis impressões negativas sobre o mesmo durante o experimento.

O gráfico 9 refere-se a facilidade de regulagem dos cintos de sustentação. Os utilizadores do experimento com o acessório modelo "C" atribuíram um relevante score de pontos em concordância com a afirmativa em questão (6 votos) e nenhuma opinião contrária. Esta aceitação pode estar vinculada ao sucesso que os participantes desse experimento obtiveram no procedimento de balanceamento do equipamento.

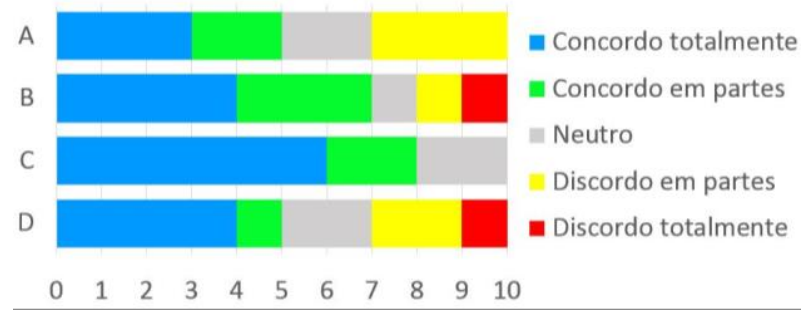

Gráfico 9- As regulagens do cinto de sustentação (arnês) são fáceis de utilizar.

Uma provável explicação estaria na forma com que os elementos de regulagem desses modelos se apresentam. Os acessórios dos cintos "C" e "B" (presilhas, fivelas, alças) se revelam em cores distintas do restante da peça. Além disso, suas formas tradicionais (frequentemente encontradas em mochilas escolares, por exemplo) provavelmente facilitaram na identificação, tornando menos complexo o procedimento de ajuste ao corpo.

A afirmativa apresentada no gráfico 10 refere-se ao fácil desprendimento do gancho do cinto ao suporte de sustentação de cada equipamento. Este procedimento demonstra-se muito importante pois o usuário, em uma situação real de trabalho, deve conseguir se soltar imediatamente do equipamento mediante imprevistos como: enxames de insetos, encontro com animais peçonhentos ou até mesmo incêndio no motor. Mais uma vez não houve um consenso entre os participantes, o que demonstra
Realização:

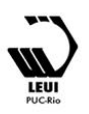




\section{$16^{\circ}$ \\ ERGODESIGN USIHC CINAHPA}

que é provável que existam problemas no uso deste acessório. Enfim, foi observado que os utilizadores do cinto modelo " $\mathrm{D}$ " atribuíram uma leve concordância com a negativa em relação aos demais, fato este que corrobora com observações relatadas em estudos anteriores sobre seu desenho, que apresenta-se um tanto confuso.

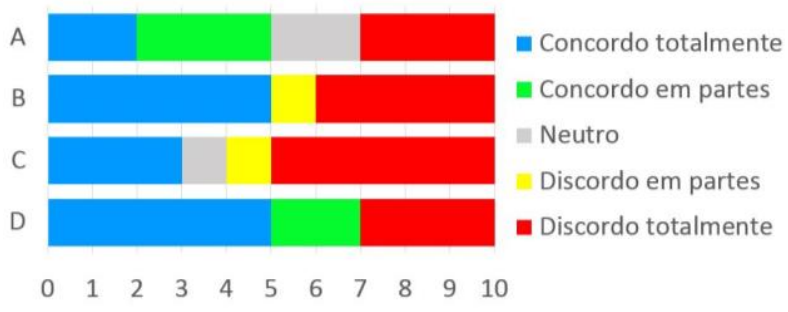

Gráfico 10 - O gancho que prende o cinto de sustentação (arnês) à roçadeira não permite o fácil desprendimento do equipamento.

Finalmente, os gráficos 11 e 12 apresentam as somatórias das afirmativas positivas e negativas. Pode-se observar considerável número de concordâncias com as afirmações positivas entre os sujeitos que realizaram o experimento com o equipamento modelo "C". Em contrapartida os utilizadores da interface oferecida pelo equipamento modelo " $\mathrm{D}$ " atribuíram menor média de concordância entre os demais (Gráfico 11). O mesmo desfecho pode ser imputado aos dados apresentados no gráfico 12, que apresenta a somatória das opiniões de acordo ou desacordo com as afirmações negativas.

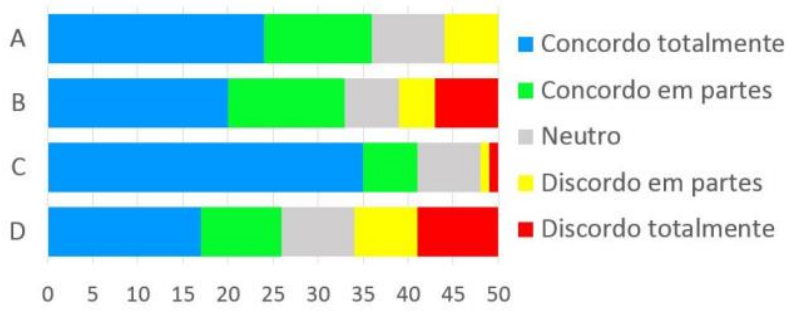

Gráfico 11 - Somatória das afirmações positivas. $16^{\circ}$ Ergodesign - Congresso Internacional de Ergonomia e Usabilidade de Interfaces Humano Tecnológica: Produto, Informações Ambientes Construídos e Transporte

$16^{\circ}$ USIHC - Congresso Internacional de Ergonomia e Usabilidade de Interfaces Humano Computador

CINAHPA | 2017 - Congresso Internacional de Ambientes Hipermídia para Aprendizagem.

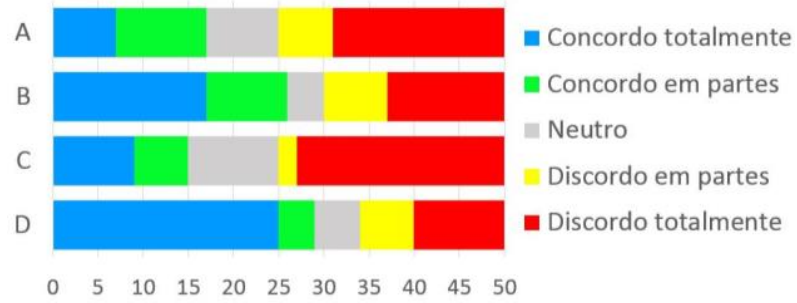

Figura 12 - Somatória das afirmações negativas.

\section{Considerações finais}

O presente trabalho apresenta resultados que afirma a importância de se considerar estudos de satisfação de usuários no pós uso de sistemas de sustentação de roçadeiras laterais motorizadas.

Ademais o experimento permitiu obter informações sobre diferentes níveis de satisfação de cada interface, impossíveis de serem verificados em etapas de observação da atividade, o que pode tornar mais fácil e evidenciação de possíveis falhas ou acertos no projeto de cada sistema. De maneira geral os sujeitos participantes do experimento com o conjunto de interfaces proporcionadas pelo equipamento modelo "C" demonstraram-se mais satisfeitos em relação aos demais. Por outro lado os sujeitos que participaram do estudo com a máquina modelo " $D$ " apresentaram maior média de insatisfação. Todas as respostas atribuídas pelos 4 grupos apresentaram níveis de coerência que corroboraram com as conclusões observadas em estudos anteriores de eficiência e eficácia dos mesmos equipamentos. Os resultados obtidos neste estudo poderão servir como ferramenta de auxílio no desenvolvimento de novos projetos de sistemas de sustentação de roçadeiras ou mesmo no aprimoramento de produtos já existentes, contribuindo assim para que empresas do setor possam projetar artefatos mais ergonômicos e de fácil utilização. Estudos envolvendo o uso efetivo em campo, bem como a aplicação de questionários que visam a identificação de possíveis desconfortos na atividade com estes equipamentos, serão implementados em experimentos futuros, buscando averiguar maiores detalhes sobre a eficiência ergonômica de cada sistema.

\section{Referências Bibliográficas}

BROOKE, J.. SUS: a "quick and dirty" usability
Realização:

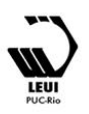




\section{$16^{\circ}$ \\ ERGODESIGN USIHC CINAHPA}

$16^{\circ}$ Ergodesign - Congresso Internacional de Ergonomia e Usabilidade de Interfaces Humano Tecnológica: Produto, Informações Ambientes Construídos e Transporte

$16^{\circ}$ USIHC - Congresso Internacional de Ergonomia e Usabilidade de Interfaces Humano Computador

CINAHPA | 2017 - Congresso Internacional de Ambientes Hipermídia para Aprendizagem. scale. In P. W. Jordan, B. Thomas, B. A. Weerdmeester, \& A. L. McClelland (eds). Usability Evaluation in Industry. London: Taylor and Francis, p. 189-194, 1996.

FATHALLAH, Fadi A. Musculoskeletal disorders in labor-intensive agriculture. Applied ergonomics, [S.L.], v. 41, n. 6, p. 738-743, 2010.

FIEDLER, Nilton Cesar et al. Avaliação das Posturas Adotadas em Operações Florestais em Áreas Declivosas. Floresta e Ambiente, [S.L], v. 18, n. 4, p. 402-409, 2011.

GÖBEL, Matthias. 2011. Empathy Meets Engineering: Implanting the User's Perspective into a Systematic Design Process. In: W. Karwowski, M. Soares and N. Stanton (Eds.). Human Factors and Ergonomics in Consumer Product Design: Methods and Techniques. CRC Press, 161-175.

GONZAGA, Maria Cristina. O uso de luvas de proteção no corte de cana-de-açucar. 2004. $98 \mathrm{f}$. Dissertação (Mestrado) - Curso de Engenharia Agrícola, Unicamp, Campinas, 2004.

GOVERNMENT SOUTH AUSTRALIA. Brush cutter safety: adjusting the saw and harness. Safeguards, Adelaide, v. 1, n. 1, p.1-2, jun. 2000.

ISO 9241-11. 1998. Ergonomic requirements for office work with visual display terminals (VDTs). Part 11: Guidance on usability. Geneva, Switzerland, International Organization for Standardization.

ISO 11806-1. 2011. Agricultural and forestry machinery - Safety requirements and testing for portable, hand-held, powered brush-cutters and grass-trimm

ISO 20282-1. 2016. Ease of operation of everyday products - Part 1: Design requirements for context of use and user characteristics. International Organization for Standardization.
JORDAN, P.W. 1998. An introduction to usability. London: Taylor \& Francis.

LANUTTI, Jamille N. de L. et al. Usabilidade de objetos de uso cotidiano: comparativo de técnicas de avaliação subjetiva (sus e ds). in: Congresso Internacional de Ergonomia e Usabilidade de Interfaces Humano-Tecnologia: Produto, Informações, Ambiente Construído e Transportes, 13., 2014, Juiz de fora. anais... . Juiz de fora: Ufjf, 2014. p. 1 - 11.

MCCURDY, S.A., SAMUELS, S.J., CARROLL, D.J., BEAUMONT, J.J., MORRIN, L.A. Agricultural injury in California migrant Hispanic farm workers. Am. J. Ind. Med.[S.L], v.44, n.3, p.225-235, 2003.

MEYERS, J.M., MILES, J.A., FAUCETT, J., JANOWITZ, I., TEJEDA, T.G., KABASHIMA, J.N. Ergonomics in agriculture: workplace priority setting in the nursery industry. Am. Ind. Hyg. Assoc. J. [S.L], v.58, n.2, p.121-126, 1997.

NIELSEN, Jakob. 1993. Usability Engineering. Boston: Academic Press.

NORMAN, Donald A. 2006. O design do dia-adia. Rio de Janeiro: Rocco

POLETTO FILHO, José Antonio. Análise dos Riscos Físicos e Ergonômicos em Roçadora Transversal Motorizada. 2013. 165 f. Tese (Doutorado) - Curso de Faculdade de Ciências Agronômicas, Universidade Estadual Paulista "Julio de Mesquita Filho" - Unesp, Botucatu, 2013.

PREECE, J.; Rogers, Y. \& Sharp, H. 2002. Interaction design: Beyond human computer interaction. Chichester, UK: John Wiley and Sons Inc.

VERGARA, Lizandra Garcia Lupi et al. Análise Ergonômica da atividade de Jardinagem e Paisagismo. Revista Eletrônica Produção em Foco. Joinville, v.2, n.1, p.85-105, 2012. 